\title{
CAN THERE BE A SCIENCE OF PSYCHOLOGY? ARISTOTLE'S DE ANIMA AND THE STRUCTURE AND CONSTRUCTION OF SCIENCE
}

\author{
ROBERT J. HANKINSON \\ https:/ /orcid.org/0000-0003-4131-3233 \\ University of Texas at Austin \\ Department of Philosophy \\ Austin, Texas \\ United States \\ rjhankinson@austin.utexas.edu
}

\author{
Article info \\ CDD: 185 \\ Received: 01.04.2019; Accepted: 02.09.2019 \\ DOI: http://dx.doi.org/10.1590/0100-6045.2019.V42N4.RH
}

\section{Keywords \\ Aristotle \\ Psychology \\ Soul \\ Teleology \\ Science}

Abstract: This article considers whether and how there can be for Aristotle a genuine science of 'pure' psychology, of the soul as such, which amounts to considering whether Aristotle's model of science in the Posterior Analytics is applicable to the de Anima.

"Clearly it is the business of the phusikos to study soul, but as not being independent of matter". Aristotle, Metaph. E.1, 1026a4-6 (cf. Resp. 480b23-30).

"Only the parts of the form are parts of the formula, and this is a formula of what is universal". Aristotle, Metaph. Z.10, 1035b33-4. 
"The end is where we start from".

T.S.Eliot, Little Gidding.

\section{1: Preliminaries}

Aristotle sets great store by the investigation into the soul, or psuchê. At the beginning of de Anima, his detailed philosophical treatment of the subject, he writes:

We suppose that knowledge (eidêsis) is one of the fine and honorable things; and that one type of it is better than another in view of its exactness $^{1}$ (akribeia), or because it has better and more wonderful objects; and on both of these grounds we may reasonably place knowledge of the soul among the primary types of knowledge. Moreover, it seems that knowledge of it contributes greatly to all kinds of truth, but particularly to that regarding nature (phusis), since it is, as it were, a first principle (archê) of animals. We seek to investigate and understand both its nature and its substance [or essence: ousia], ${ }^{2}$ and then what its properties are, of which some seem to be proper to the soul, while others belong because of it to the animals as well. (1: de Anima 1.1, 402a1-10, translations my own)

\footnotetext{
${ }^{1}$ For a justification of this translation here, see $₫ 4$ below; akribeia is also variously rendered as 'precision' and 'accuracy'.

2 The translation of this crucial technical term is a delicate and controversial issue. I will be using both 'substance' and 'essence' to render it, but will also simply present the transliterated term itself.
} 
All of this is pointed, even if it is expressed in the grandiloquent manner of Aristotelian exordia. Understanding of the soul is (or should be) capable of precision and exactitude; and it is of salient importance, since the soul is a first principle of animal life (indeed, of life more generally conceived to include plants; not to mention God). This claim immediately calls to mind Aristotle's theoretical strictures on the nature of properlyconstructed sciences, or epistêmai. As the opening chapters of Posterior Analytics make clear, well-founded sciences proceed from necessarily true, basic, explanatory first principles, archai, and then deduce from them, as necessarily consequent theorems, propositions concerning the per se attributes of the items whose essential properties the axioms encode. ${ }^{3}$ These are the properties mentioned in text 2, necessary, albeit non-essential, attributes of the substances themselves. The soul would appear to be a paradigm candidate for formal expression in a completed Aristotelian science.

Still, there are problems with this. The soul is notoriously hard to get clear about; there is not even any agreement as to what type of thing it is, if indeed it is a thing of any kind at all (the rest of book one of de Anima lays out and criticizes the multifarious and conflicting views of his predecessors). The inquiry seems to be similar in form to many others, "being about essence and what something is" (402a12-13), so one might expect there to be a single method of circumscribing and describing the essences or substances in question "just as there is of demonstration (apodeixis) of their per se attributes" (402a15). But that may not be the case. Perhaps different types of subject-matter must be established in different ways, and even if not, it is unclear where we ought to start from (402a16-22). Two questions require settling: first, what

${ }^{3}$ See Posterior Analytics I.2-6. 
category does the soul fall under? Is it a substance, or is it rather a quality or a quantity, or indeed something else (402a23-5)? And is it something which has its existence in potentiality, or is it a fully-actualized substantial being (402a25-b1)? Finally, there are pressing questions as to whether it is unitary, or consists in parts (and if so, what sort of parts), and whether all souls are the same in species, or generically similar, and whether there is a single account (logos) of soul in general, or whether each type of thing has its own type of soul (402b1-9).

Aristotle, then, rehearses a formidable array of difficulties that stand in the way of even starting this noble undertaking (and there are still more besides). My project is to show how far Aristotle's procedural methodology, as outlined in 1.1, and followed through in the rest of de Anima, can be seen as a preliminary to the construction of properly-articulated Aristotelian science; and to the extent to which it can, what sort of science the results of the inquiry would ultimately yield.

The methodology sketched in De Anima 1.1 is also adumbrated elsewhere. The generally-held views both of the general run of humanity and of the so-called experts of "the many and the wise" as he sometimes puts it ${ }^{4}$ - will suggest preliminary circumscriptions of the subject matter in question, and the formulation of provisional definitions (compare the 'nominal definitions' of Post.An 2.10 here). A crucial part of this process consists in concentrating on the most general attributes of the subject at issue, the soul, or perhaps rather what the soul is supposed to account for, the features that distinguish living things from the inanimate:

4 Topics 1.1, 100b22-4; the preliminary chapter distinguishing dialectical from demonstrative reasoning. 
It seems not only that knowing what something really is contributes to the investigation of the causes of substances (ousiai), ... but also conversely the attributes (sumbebêkota) make an enormous contribution to grasping what the thing really is. For when we can give an account of what all or most of its attributes apparently are, we will also be in the best possible position to talk about its essence (ousia). For what something is is the origin (archê) of every demonstration; so definitions which do not allow us to understand the attributes, or at least make a reasonable approximation to them, are clearly all merely argumentative and vacuous. (2: 1.1, 402b16-403a2)

Ordinary ways of describing things, and more reflective accounts that are based upon them, have some preliminary claim to be taken seriously; indeed de Anima itself provides part of the justification for this view. Animals are constructed so as to register their environments in ways conducive to helping them navigate their way around them; but they could not do so if they did not, generally, register them accurately. ${ }^{5}$ Ordinary beliefs, and ordinary ways of categorizing, can thus serve as a provisionally reliable basis for the investigation into the basic structures of things, investigations which yield proper essential definitions, in terms of which, as the last sentence of $\mathbf{2}$ makes clear, the derivative attributes, the things from which we started, can be understood. Which is what, for Aristotle, science (epistêmê) properly is. In the case of the soul, everyone recognizes that there is a fundamental distinction between living and non-living things: that is what reference to the

${ }^{5}$ See Barnes (1987). 
soul is supposed to indicate. But it is far harder to say just what this distinction essentially consists in, and how it is to be explained and its specific features regimented. In a sense, all of Aristotle's biology is devoted to this project.

Aristotle sees his conceptual investigations in de Anima as making a contribution to the ultimate fulfilment of that goal. It is rendered particularly difficult by the extreme generality of the investigation, and the large number of fundamental questions that need to be resolved before we can even get started. Not least among these are those concerning the relationship of the various forms of life to one another, and how these relationships should structure our account of the basic, explanatory properties ultimately at issue (most people have simply concentrated on the human soul, and thus ignored these crucial issues: de Anima $1.1,402 \mathrm{~b} 3-8)$. Related to this is the question of whether in talking of the soul we are talking of a substance, or some set of attributes in some other category (402a23-b1), and whether souls (or soul-properties) should be thought of as partitioned, or hierarchically-organized (402b1-3) - or, conceivably, both.

All of these questions are given some sort of answer in the course of de Anima. In answering them, Aristotle offers insights into the structure of science itself, in particular the extent to which, and under what circumstances, particular groups of properties can be thought of independently of the natures of the things whose properties they are. Specifically, are there any attributes peculiar to the soul itself, or should they be considered only in connection with the bodies of which they are the properties? For Aristotle these are not merely scholastic questions. There should be correct answers to them, which will be correct because of fundamental, objective features of the way the world really is. This in turn casts some light on the relation between super- and subordinate sciences, and the 'mixed sciences', 
physical sciences which borrow some of their axioms from the formal, abstract sciences of arithmetic and geometry.

\section{THE Formal MODEL AND THE GENERALITY OF SCIENCE: SOME PRELIMINARY QUESTIONS}

By 'demonstration' (apodeixis) I mean a
scientific deduction (sullogismos epistêmonikos),
and by 'scientific', one which is such that
when we have it we understand...
demonstrative understanding must be from
things which are true, primary, immediate, and
better known than (gnôrimôtera), prior to, and
explanatory of the conclusion; in this way the
first principles (archai) will be appropriate
(oikeial) to the conclusion". (3: Post.An. 1.2,
71b19-23)

So Aristotle begins his formal characterization of the proper nature of science, in terms of six features the axioms must exhibit. ' 'Better known than', ' 'gnôrimôtera', is glossed a few lines later:

Things are prior and better known in two ways: what is (a) naturally prior is not the same as what is (b) prior relative to us, and

\footnotetext{
${ }^{6}$ See Barnes (1994) ad loc.

${ }^{7}$ I retain this translation (as opposed to 'more familiar', or 'more knowable'; see Barnes (1994, pp. 95-6)), as being perhaps the least tendentious. Elsewhere I have favoured the barbarous 'more cognitive', since that at least tries to capture the fundamentally causal flavour of the notion: things that are gnôrimos are things that are productive of knowledge in one way or another. They are 'more knowledgy'.
} 
nor is what is (a) < naturally $>$ better known the same as what is (b) better known to us. (4: Post.An. 1.2, 71b33-72a1; cf. Topics 6.4, 141a25-142a15; Phys. 1.1, 184a9-b14, esp. a1721; NE 1.4, 1095b2-4; An.Pr. 2.23, 68b35-7; etc.).

The two sorts of priority inhabit opposite ends of the epistemic spectrum: it is by way of the (b) class of items that we come eventually to grasp those of the (a) class; but only when we have grasped the latter are we fully in a position to understand the former. The (b)-items are said to be "nearer to perception" and 'particulars', while the (a)items are universals (72a1-6); and it is those which are genuinely explanatory. ${ }^{8}$ Go back to text 2 : it is by gathering those attributes which we take to be distinctive of and proper to living things that we will be able to get clear about what life actually is.

Which brings me to consideration of what it is for premises to be appropriate (in the appropriate sense) for their conclusions. But first we should consider three more general questions concerning the scope, structure, and constitution of Aristotelian science:

(A) How general should a science be? This falls into two parts:

8 Consider the example of the moon at 1.13, 78b4-11: astronomers infer that it is spherical because of the succession of its phases; but it exhibits those phases because it is spherical (and shines by reflected light, and...). The moon's phase-structure is prior to its sphericity in the ordo cognoscendi, but not in the ordo essendi. Note also 1.9, 76a18-20: "someone who knows from things higher up knows better, since he knows from more primary things when he knows on the basis of causes which are not themselves subject to explanation". 
A1. At what levels within it should the explanations take place?

and

A2. How broadly should the science cast its net?

A1 and A2 both concern an indeterminacy in the notion of the 'appropriate' explanation for some property's holding of a subject when there are several intervening middle terms.

(B) In relation to this, Aristotle will sometimes invoke the 'most general' (koinotata) properties of the items in the domain (e.g. at $D A 2.1,412 \mathrm{a} 3-6$ ), saying that we should begin our enterprise of constructing the science from them. But how general can they be and still function as explanatory for the domain in question? The case of 'first philosophy' is instructive: we can indeed investigate the most basic principles of being as such, but they will not give rise to a single, architectonic science which provides a deductive account of everything (Metaph. Г1-3, 1003a211005b1). ${ }^{9}$

And again

(C): Can one science be a proper part of another? If not,

(i) What is the proper understanding of the 'mixed sciences', such as optics, mechanics, astronomy, and harmonics? ${ }^{10}$

9 The nature, scope, and proper interpretation of Aristotelian metaphysics is a vast and controversial topic; Barnes (1995) offers a sceptical overview.

10 The 'mixed sciences' make use of relationships drawn from the abstract mathematical sciences in their explanations of physical 
And

(ii) What does the celebrated prohibition on 'kind crossing' amount to?

These in turn raise further questions. In Aristotle's account, there seem to be two opposing pressures at work, one tending towards maximal generality, the other towards maximum specificity: How (if at all) can these be reconciled? In any case, what unifies a science? There is also a formal issue. If science is about essences, and there are essences only (strictly speaking) of substances, then it looks as though sciences will have to be tightly domainrestricted, as well as confined to particular types of substance. ${ }^{11}$ But it seems as though that can't be right, since if it were, there could then be no mixed sciences, and no general science of life (or of animals), of the sort that Aristotle clearly countenances at $D A 1.1,402 \mathrm{a} 16-403 \mathrm{a} 2$ (cf. PA 1.1, 639a15-b6, discussed below, \5; and Cat. 5, 1b1318, 2b7-29, 3a13-24 on levels of 'secondary substance'). Even more worryingly, there could be no abstract sciences such as arithmetic and geometry in the first place to provide the borrowed mathematical content for the mixed sciences, since they do not, for Aristotle, deal with separable, Platonic substances as such at all. ${ }^{12}$

phenomena, as in the case of the explanation of the moon's phase structure (n. 8 above); see Lennox (2005), Hankinson (2005).

11 Only substances have an essence in the sense of a to ti en einai, a 'what-it-is-to-be' of something - but other attributes have a ti esti, a 'what it is'.

12 On Aristotle's philosophy of mathematics: see usefully Lear (1982), Mueller (1970), Barnes (1985). 


\section{Physics AND THE Formal SCIENCES: Form AND MATTER, DEFINITION AND GENERALITY}

Let us first consider a crucial relation that Aristotle both relies upon and must make sense of: that between physics, the study of material bodies in motion, and the abstract sciences. ${ }^{13}$ In Physics 2.2, Aristotle distinguishes physics from mathematics (and metaphysics) essentially by insisting that physics deals with form as it is realized in matter. The mathematician is not concerned with lines and surfaces as they are manifested in bodies, but only as abstracted from them (Phys. 2.2 193b31-6). Thus odd, even, straight, curved, number, line and shape are all "without movement", i.e. they can be treated without any reference to things that have the capacity for movement (and rest) which form the subject-matter of physics. ${ }^{14}$ "But this is not true of flesh, bone, and man, for these are like the snub-nose and not like the curved" (194a3-7); i.e., what they are as such intrinsically involves what they are enmattered in. ${ }^{15}$ This is true of the mixed sciences: "geometry studies physical lines, but not qua physical, ${ }^{16}$ while optics studies the mathematical line, but not qua mathematical but qua physical"17 (194a10-

${ }^{13}$ Consider the first epigraph to this paper.

14 Whether the soul is physically separable, chôristos kata megethos, becomes important later on: $D A 3.4,429$ a11-12.

15 Snubness is Aristotle's standard example of something whose definition necessarily involves matter: Metaph. E1, 1025b281026a5, Z10, 1035a1-6; Soph.El. 31, 182a4-6; Phys. 2.3, 194a1-14; and $D A 3.4,429 \mathrm{~b} 14$; see Shields (2016, pp. 306-8).

16 Because lines are fundamentally physical, in that they are dependent upon the existence of physical things - if there were no physical bodies, there would no geometrical properties at all.

17 I.e., optics deals with physically manifested phenomena that obey the abstract rules of geometry. 
12). Physics is concerned with both the material and the formal (194a12-28). Moreover, it is essentially teleological: the end is the nature that directs things towards their goals (194a28-b8). The physicist, then, deals with form and essence, but neither wholly abstractedly nor wholly materially, but rather as the doctor deals with sinews, and the bronzeworker with bronze. Each is concerned with the final cause, that "for the sake of which"; but these things are separable only formally (i.e. conceptually), and necessarily exist in matter (194b9-12). In other words, physics deals with composite substances as such, i.e. with hylomorphic compounds.

So if the natural scientist will study soul insofar as it is not independent of matter, the phusikos will treat of the definitional capacities of the soul, for self-movement, perception, metabolism and reproduction, and so on; ${ }^{18}$ but only insofar as they are exhibited in the material structures which suitable for their realization. This leaves open the possibility of there being a kind of 'pure' psychology, or science of the soul, consisting in the investigation of the relations that hold between types of functional capacity, by contrast with the 'applied' psychology, which is a part of physics. ${ }^{19} \mathrm{I}$ will return to what such a science might look like at the end of the paper; but briefly, the question turns on what, if anything, is properly proper, idion, to the soul as such, and whether such features can usefully be studied in isolation from their physical embodiments.

${ }^{18}$ For these as the defining characteristics of the Aristotelian soul, see in general $D A 2.1-5$; and $P A 1,639$ a15-27 ( $\$ 5$ below).

19 Sens. 1, 436a18-b8 offers a different, but congruent, example of a division between domains, as well as of a convergence of interests: both phusikoi and doctors of a scientific bent study health and disease, but "the former end up studying medicine, while the latter base their medicine on physical principles" (436a22-3). 
The basic issue is broached at the beginning of de Anima:

The affections of the soul (ta pathê tês psuchês) also involve a difficulty, namely whether all of them are common too to what has them [sc. the ensouled body], or whether there is something also proper to the soul itself. It is necessary to grasp this, but not easy. In most cases it seems as though it [sc. the soul] neither undergoes nor does anything without the body, like being angry, being confident, desiring, indeed in general perceiving. Although thinking seems most proper to it, if this is phantasia, or not without phantasia, then even this cannot occur without a body. So if one of the soul's functions or affections is proper to it, it could exist in separation; but if there is nothing proper to it, it will not be separable.... But all of the properties of the soul seem to exist along with the body: passion, mildness, fear, pity, confidence even joy, loving and hating. For in all of these cases the body undergoes something along with them (5: $D A$ 1.1, 403a3-19)

This poses the question of separability sharply, and in physical terms. If it turns out that even thinking (or at any rate the sort of thinking of which humans are capable) cannot take place without mental representations, and those in turn are physical in nature, ${ }^{20}$ then there will be no science of a separate soul. And if so, there will be no properties which are proper (at least in this sense) to the soul as such, since in this sense there isn't a soul as such

${ }^{20}$ See $D A 3.7,431 \mathrm{a} 14-17,431 \mathrm{~b} 2-5 ;$ 3.8, 432a3-10. 
(considered as a substance capable of independent existence) at all.

In the first sentence of the Parva Naturalia Aristotle writes:

Clearly the greatest $\mathrm{t}^{21}<$ attributes $>$ of animals, both common and peculiar, are those which are common to soul and body, such as perception, memory, passion, appetite, and in general desire, and in addition to these pleasure and pain. For these belong to pretty much every animal. In addition to these, there are some which are common to everything which has a share in life, while others belong only to some animals. The most important of these are four pairs: waking and sleep, youth and old age, inhalation and exhalation, life and death. (6: Sens. 1, 436a7-15)

Furthermore,

Perceiving (to aisthanesthai) is an idion neither of the body nor of the soul, since of that of which there is potentiality, there is actuality too, and what we call sensation (aisthêsis), as an energeia, is a movement of the soul by means of the body. So it is clear that this affection is not an idion of the soul, and nor is a body without soul capable of perceiving. (7: Somn. 1, 454a8-11).

Strictly, then, none of these things (not even thought) are idia of the soul. But even so, there may still be a sense in which they can be treated as if they were, in much the same

21 'Greatest' here in the sense of 'most widely distributed'. 
as way as, for Aristotle, there would be no numbers if there were no denumerable things, but for all that we can treat of numbers in abstraction from the things they enumerate. I will return to this later. But for now, let us turn to the issue of akribeia, and its relation to explanatory generality.

\section{AKRIbEIA AND THE SCIENCES: The Nature OF 'EXACTNESS'}

The first sentence of text 1 relates the excellence of a science to its degree of exactness, and makes this one reason for the superiority of the science of the soul ( $D A$ 1.1, 402a1-4). Here is how he clarifies what exactness amounts to when applied to different scientific disciplines:

One science is more exact and prior to another (a) if it is concerned both with the facts and the reason why, ... (b) if it is not said of some underlying subject, while the other is said of an underlying subject (arithmetic is more exact than harmonics in this way); or (c) if it proceeds from fewer items, while the other involves some additional posit (as arithmetic is more exact than geometry). (8: Post.An. 1.27, 87a31-5)

Being "concerned both with the facts and the reason why" characterizes, among other things, the mixed sciences, such as for example mathematical astronomy (by contrast with what Aristotle describes as 'nautical astronomy': Post.An. 1.13, 78b34-79a6), and in these disciplines the reasons why (or at least some of them) are supplied by the superordinate, abstract science. But any science worthy of the name deals with the reason why; as $\mathbf{3}$ insists, proper sciences proceed from principles which serve to explain 
their conclusions. Still, the example given to illustrate distinction (b), whether or not the science is "said of some underlying subject", also invokes the same relation as it applies to a mixed science: arithmetic, which supplies the explanatory heft for harmonics (in the form of the theory of ratios), is more exact than the latter because it abstracts from the latter's matter. This coheres with the distinction already posited, between 'pure' and 'applied' psychology, between treating things as being idia of the soul even if in some basic metaphysical sense they are not, given that there is no substantially-separable soul.

We may pursue the account of exactness further. Earlier, Aristotle wrote:

If a demonstration that proceeds from a principle is more exact than one which does not..., then a demonstration which proceeds more from a principle is more exact than one which does so less. But a more universal demonstration is of this type.... For instance, if you need to demonstrate $\mathrm{A}$ of $\mathrm{D}$, and the middle terms are $\mathrm{B}$ and $\mathrm{C}$, but $\mathrm{B}$ is higher, so a demonstration through $\mathrm{B}$ will be more universal. (9: Post.An. 1.24, 86a16-21)

Any demonstration, by definition, "proceeds from a principle": so what does the first sentence mean? The contrast might be between genuine, scientific, demonstration, and mere 'dialectical demonstration', the sort of quasi-demonstration that involves arguing from merely provisionally-accepted premises, which Aristotle deals with in the Topics. Arguments of this sort may well be deployed to get us from the phenotypical surface characteristics of things to their underlying genotypical explanations, in the manner suggested by text 2 . 
But that is hardly to the point here. The idea is rather that some principles are more fundamental than others; and demonstrations which start from these can be characterized, loosely but intelligibly, as proceeding "more from a principle". Indeed, archê here might perhaps better be rendered simply as 'origin' (which is perhaps its basic sense), and so be allowed to cover terms as well as propositions (see 2 above; and $\mathbf{1 2}$ below). In the schematic example given, what matters is which of the middle terms mediating between the subject and the predicate of the conclusion actually accounts for why the predicate does indeed hold of it. We are dealing with a chain of syllogisms, which are genuinely explanatory and whose premisses encode real relations between items. The question then is: Which one do we fix on as giving the proper explanation of the conclusion? Aristotle considers this question in more than one place, and gives different, apparently inconsistent, answers. ${ }^{22}$ Here, he seems unequivocally to say that the syllogism involving the intermediate term which is closest to the highest principle will be the most fully explanatory, and hence most 'exact'.

Earlier still, Aristotle considers a slightly different case. A 'particular demonstration' might show that isosceles triangles have a certain property (the angle-sum $2 \mathrm{R}$, for instance), while a 'general demonstration' would involve showing that all triangles have that property; the former might seem 'more exact', in that it told you something about a more restricted class of things; but the latter is 'more universal'. Moreover, there is a fairly clear intuitive sense in which any isosceles triangle has angle-sum $2 \mathrm{R}$

22 Barnes (1994, pp. 155-6; cf. 257-8) says that in any such chain, all of the intermediate terms must figure in the full explanation, "and it is fatuous to attempt to single out any subset of these as constituting the 'real' explanation of the fact". Perhaps so, but we can make some sense of Aristotle's desire to do so. 
because it is a triangle and not because it is isosceles (85b415). ${ }^{23}$ To generalize: when you arrive at a primitive truth, where a property holds of some class just because it is what it is, then you have explained why the property in question holds of some sub-class of that class:

We know best [why something is the case] when we know that this holds, and not because something else does. (11: 1.24, 85b3638)

This is opaque; but it is presumably glossed by:

To prove something more universally is to prove it through a middle term which is nearer to the principles; and the immediates are nearest; indeed they are the principles. (12: 1.24, 86a14-15).

But this too involves difficulties. In the case of propositions which convert, there are different ways in which terms might be arranged so that one is 'nearer' (indeed, immediate) to the axioms. If one wants to know why Fs are Gs, one does so by isolating the highest level of generality $\mathrm{H}$ such that it is true that everything $\mathrm{F}$ is $\mathrm{H}$, and all and only $\mathrm{Hs}$ are Gs. But this is insufficient, precisely because the universal linking $G$ and $H$ is 'commensurate', i.e. it expresses an equivalence. ${ }^{24}$ As such two valid

${ }^{23}$ The point is made again, in the case of the external angles of the isosceles equalling 4R, at 85b-86a3; this allows Aristotle to move to a higher level of generality, namely that of rectilinear plane figure (since all such figures have an external angle-sum of $4 \mathrm{R})$; see 13 below.

24 For a deflationary view of the role of 'commensurate universals' in Aristotelian science, see Barnes 1994, pp. 258-9. For 
syllogisms are constructible: (1) All Fs are $\mathrm{Hs}$, all $\mathrm{Hs}$ are Gs, hence all Fs are Gs; and (2) All Fs are Gs, All Gs are Hs, hence all Fs are Hs. At most one of these can be properly explanatory, in that it will encode the proper direction of real (as opposed to merely epistemic) explanation. ${ }^{25}$

The claim is that, for a sequence of propositions $\mathrm{AaB}$, $\mathrm{BaC}, \mathrm{CaD}, \mathrm{DaE}+\mathrm{AaE}$ (where ' $\mathrm{A}$ ' is the major term, ' $\mathrm{E}$ ' the subject), ${ }^{26}$ provided that each of them represents (in the case of converting terms) the appropriate direction of explanation, then $\mathrm{E}$ will be A (ultimately) because it is B, and Bs are essentially and immediately As.

However, consider the following:

Is the explanatory middle term for the various particulars that which is in the direction of the primary universal or that which is in the direction of the particulars? Evidently that which is nearest to the particular for which it is the explanation, since this is the cause of the first one falling under the universal. For example, $\mathrm{C}$ is the cause for $\mathrm{D}$ of being $\mathrm{B}$, and so $C$ is the cause for $D$ of being $A$, and $B$ is the cause of being A both for $\mathrm{C}$ and for itself. (12: Post.An. 2.18, 99b8-14)

This is surprising, and conflicts both with 1.24 , and with this, which comes only a few lines earlier:

a recent interpretation which takes them much more seriously, see Angioni 2018, pp. 175-182.

${ }^{25}$ Consider again the relation between the moon's sphericity and its phases: n. 8 above.

26 I.e., such that ' $\mathrm{AaB}$ ' is read as 'A belongs to all $\mathrm{B}$ ' or, equivalently, as 'All Bs are As". 
The explanation, that of which it is the explanation, and that for which it is the explanation, are inter-related in the following way. If the particulars are taken separately, then that of which it is explanatory has a wider extension <than each of them>, e.g. having the sum of the exterior angles equal to $4 \mathrm{R}$ extends further than triangle or quadrilateral; but if they are all taken together it is co-extensive with them - i.e. all the figures which have external angle-sums of $4 \mathrm{R}$. And the same goes for the middle term: the middle is definitional of the first extreme, which is why every science come to be through definitions. (13: Post.An. 2.16, 99a1722)

Aristotle's account seems wholly inconsistent; and the cause of this is, apparently, the 'two opposing pressures' mentioned earlier ( $\$ 2)$, one towards greater generality, and the other towards greater specificity. Let us approach those matters from a different standpoint.

\section{GENERALITY, EXPLANATION, AND THE SCIENCE OF THE SOUL}

At the very beginning of Parts of Animals (1.1, 639a15-27), Aristotle poses a general question about where we should start collecting the basic properties whose existence and inter-connections our science is ultimately supposed to explain. Should we look first to the infima species? Or should we rather begin by establishing the common attributes (sleep, growth, death, respiration, etc.: Sens. 1, 436a7-15, 6 above), and then narrow them down (cf. 1.5, 645b4-14; and 
$D A$ 1.1, 402b1-16)? The former might seem needlessly repetitious; but on the other hand, some general terms (e.g. 'locomotion') are too general; their species are importantly different ("flying, swimming, walking, crawling"), and done with different parts (639a27-b6; cf. 1.4, 644a14-22: there is no useful general class covering both water-dwelling and flying animals, even though they share analogously certain salient characteristics). This prompts another fundamental question, adumbrated in text 2: Should we simply state the phenomena first, and only then seek to explain them (639b6-11)? The answer is an unequivocal 'yes' (640a14-15; cf. 5, 645b1): we first collect the common per se attributes, then determine their causes. ${ }^{27}$ But even so, questions remain: at what level should we collect the phenomena? And what sort of cause are we looking for?

For there are importantly different ways of doing science. My epigraph from Metaph. E1 1026a4-6 distinguished the concerns of the natural scientist, the phusikos, from those of a more generally theoretical nature; and the example given was precisely that of the investigation into the soul. The distinction between natural and the theoretical is partly marked by a difference in the nature and abstractedness of the subject-matter; but it is equally (and relatedly) characterized by a concern with a different kind of causal explanation. At $P A 1.1,639 \mathrm{~b} 11-21$, Aristotle discusses the different types of cause and their relative ordering, and asserts unequivocally that, at least in domains in which the search for it is applicable, the final cause is the most important, and even more so in nature than in art. Moreover:

The mode of demonstration and of necessity is different in natural science and in the

27 This mirrors the practice in mixed sciences like astronomy: Post.An. 1.13, 78b34-79a16; cf. Pr.An. 1.30, 46a17-24. 
theoretical sciences... For the origin is, in the latter cases, what is, but in the former what will $b e$ : since health, or mankind, is this sort of thing, this must be, or come to be... nor can the necessity in this sort of demonstration be conjoined with the eternal, so as to say: Since this is, then that is. (14: $P A 1.1,640 a 1-7)$

Theoretical science is concerned with being, domains in which relations are necessary and eternal in a strong sense; but natural science, the domain of the phusikos (cf. Metaph. E1, 1026a4-6 again), deals with becoming, how things develop and operate in the fluid and contingent sublunary world.

This is not, however (or at least not yet), precisely the distinction we are looking for. The soul is, Aristotle says, the cause of the living body in three ways, efficient, formal and final (DA 2.4, 415b8-20). It is, traditionally, an efficient cause: the thing which makes the living body capable of movement (self-movement, along with sensation, being one of the two things traditionally attributed to the soul: $D A$ 1.2-5). It is also the form of the living body, that in virtue of which the living body is in fact alive; and moreover, it is its final cause:

Clearly the soul is also a cause for the sake of which; for just as intellect (nous) acts for the sake of something, so too does nature: and this is its end (telos). The soul is naturally this sort of thing in living things, since all natural bodies are instruments (organa) of the soul, those of animals as well as those of plants, since they are for the sake of the soul. (15: $D A$ $2.4,415 b 8-20)$ 
The soul is not, however in any general sense), a material cause. That role is fulfilled by the body, as such; and the explanandum, what is being accounted for, is the composite substance. This is of central importance, and in more ways than one. It is the composite, the living body, which is the proper subject of the science which involves soul, at all levels of generality. Moreover, the subjects of proper sciences must be substances which have essences; and as the very general characterization of the formal structure of a science shows (above, $\$ 2$ ), a science consists in the systematic presentation of the derivation of the necessarily consequent properties of the type of substance in question from its essential properties. If, then, the soul is the essence of living things as such, then it seems as though there cannot be a science of $i t$ - that would involve a categorymistake in the strongest possible, indeed Aristotelian, sense.

But things are not so straightforward. Aristotle himself appears to say that the soul itself has an essence. Consider again the last sentence of 1 : our task is to understand the soul's nature and ousia, and what its properties are, some of which are proper to the soul, while others belong to animals as well because of it. Whether we render ousia here as 'essence', or 'substance', the point remains the same: the soul itself is said to have a certain essential structure. Moreover, if it does so, it will have idia: derivative properties which are proper to it as such, as contrasted with those properties that are only properly predicated of the animal as a whole, the composite substance. As text $\mathbf{5}$ notes, the whole subject is fraught with difficulty. On the one hand it seems as though we can talk of psychological attributes simply as such; but on the other it seems that all (or at any rate very many) of them are necessarily realized in bodies, indeed in bodies of certain determinate types; and that those bodies serve an irreducibly necessary organic function. The attributes, no matter how important or 
fundamental they may be, are dependent upon the appropriate bodily vehicles for their existence.

The idia of the soul, then, would presumably be the properties of soul considered as separable (i.e. even if they are not in fact so). But separable in what sense (or senses), and from what? Given what has already been established, they must be at least conceptually separable from the body, or from the bodily organs. This opens up the possibility of a purely formal science of the soul, one which expresses the relations of dependence that holds between psychological properties conceived purely as such. It would contain only things that are (conceptually) idia to the soul, that is to say, things considered as distinguished wholly by the types of functionality involved, without reference to any of the particular necessities of enmatterment; as such, it will implicitly involve final cause relations (and explanations), and hypothetical necessity. This explains why the pathê of the soul, even if they are as a matter of fact inseparable from certain types of physical embodiment, are properly to be described as 'accounts [or: forms] in matter' (logoi en hulêt): 28

Their definitions will be of the following sort: "being angry is a movement of a body of this sort, or of a part or capacity of it, as a result of this and for the sake of that". Because of this the study of the soul, ... at least this part of it, will be the province of the phusikos. The phusikos and the dialektikos, then, will define these things differently, such as what anger is: one of them saying that it is the desire for retaliation, or something similar, the other that

28 Which is better-attested than logoi enuloi, as printed by Ross (1961), and has the virtue (for me) of stressing that the logoi can be considered separably from matter; see Shields (2016, pp. 98-9). 
it is the boiling of the blood, and heat around the heart. The latter specifies the matter, ${ }^{29}$ the former the form (eidos) and the account (logos). For while this is indeed the account of the subject at issue, it must necessarily be in this sort of matter, if it is to be instantiated. (16: $D A 1.1,403 a 25-b 3)$

This is a much-discussed, and crucially important, passage. What matters for us is that both types of definition are equally applicable, and equally appropriate, albeit in different contexts. Aristotle illustrates the distinction with the example of a house. Functionally, it is definable as a shelter to prevent damage to oneself and one's property; one person will say that it is stones, bricks and wood, another that it is "the form in these for the sake of that" (403b3-7). So is the phusikos the one concerned with form, the one concerned with matter, or the one concerned with both (403b7-9)? Indeed, is anyone is concerned with merely material properties as such (403b9-10)? In fact, "the phusikos [will be concerned with] all of these things which are such as to be functions and properties of this sort of body, and this sort of matter" (403b10-12; cf. Phys. 2.7, 198a21-4: the phusikos deals with all four causes). ${ }^{30}$

29 Not just the material, blood, but blood in a condition of ebullition: this is the substrate for the formal, affective properties.

30 This brief discussion parallels that in Metaph. Z.3 concerning the nature of ousia; and that puzzling document (as well as much of what follows in that notoriously problematic book) is relevant to our inquiry here. So too is $D A 2.2,414 \mathrm{a} 12-19$ : "the soul is this thing with which we live, and perceive, and think, in the primary sense: and as such it will be a formula and a form, and not matter or a substrate. For substance is said, as we have said, in three ways, of which one is the form, one the matter, and one that which is composed of both of them. And of these, the matter is the capacity (dunamis), the form the actuality (entelecheia), since that 
But even if the phusikos deals with all aspects of the composite substance, there may still be a role for a purely formal account of what it is that makes it formally speaking what it is. It is this which $D A$ seeks to provide, in its treatment of the idia of the soul. That this is, indeed, its function is confirmed by the opening, transitional words of de Sensu, which signal a movement in the direction of the more materially-grounded, as well as towards a consideration of the characteristic activities, and how they should be parcelled out:

Having made the appropriate distinctions in the case of the soul in and of itself, and with each of its distinct capacities, we need now to investigate animals, and indeed all living things, to see which are their proper and which are their common activities (praxeis). (17: Sens. 1, 436a1-5; compare 6 and 7 above; $P A 1.1,639 \mathrm{a} 27-\mathrm{b} 6)$

Let us then now turn, finally, to these distinctions, and to how they are to be appropriately made.

\section{DEFINING THE SOUL: THE CONSIDERED ACCOUNT}

Book 1 of de Anima, in spite of its general aporetic cast, does establish that the soul, at least in animals, is usually associated with, and implicated in the production of, the properties of autonomous movement and sensation. But when he finally turns to the positive account in Books 2

which is made out of both of them is the ensouled thing, and the body is not the actuality of the soul, but rather this is [the actuality] of the body". 
and 3, Aristotle begins by offering what he calls the 'most general definition ${ }^{31}$ (koinotatos logos)' (DA 2.1, 412a2-4), of the soul, which ranges far more widely. This is given in three subtly different, and cumulative, forms:

D1: "The soul is the substance (ousia), in the sense of the form (eidos) of the natural body which has life in it potentially; but the ousia is actuality (entelecheia), and so it will be an actuality of this sort of body" $(2.1,412 \mathrm{a} 19$ 22).

D2: "The soul is the first actuality of a natural body which has life in it potentially; and this sort of body is so in so far as it is instrumental (organikon)" (2.1, 412a27-b1).

D3: "So, if we must affirm something general about every soul, it would be the first actuality of the natural instrumental body". (2.1, 412b4-6)

These definitions and their inter-connections have been the subject of much exegesis and controversy. They are 'most general' in the sense that they will cover soul in any and all of its Aristotelian forms. They will apply to absolutely anything which is alive, including vegetables, where there is no sensation whatever (or not for Aristotle at any rate), and autonomous movement only in a severely attenuated (but for all that still genuine) sense. There is however another sense of 'most general' which these definitions as such do not capture (although they are perfectly compatible with it): the specific soul-functions which anything which has a soul

31 Or 'account': these 'definitions' are not presented in what is elsewhere the canonical genus-differentia definitional form, which consists in first enunciating the general class to which the item in question belongs, then specifying how it essentially differs from everything else in the genus (Top. 1.5, 101 b38 ff.; 6.4, 141b26). 
of any kind will of necessity have, namely those which Aristotle calls 'nutritive' or 'reproductive' (threptikê or gennêtikề), and to which we will turn shortly. ${ }^{32}$

D1 identifies the soul with substance (or essence), but in the particular sense of the form of a natural body, and not just any natural body, but one which is such as to be capable of being alive. That might seem to be less than helpful, indeed trivial: anything which has a soul will be such as to be capable of being alive. But it is not entirely nugatory. Souls, on this account, or at any rate these types of soul, will be properties of bodies; and while that does not in and of itself directly rule out the possibility of there being disembodied souls in some way or other, it does entail that our basic concern is with composite substances, animated bodies. D1 also specifies that souls are forms: what makes the things, the composites, properly the things that they are. Finally D1 emphasizes that to be an ousia (in this sense) is to be an entelecheia, the fully-actualizing structure, or as Ross suggests, the 'completion', of something. ${ }^{33}$ This sort of ousia is not a substance as such, a basic countable entity in the ontology, but rather what (formally speaking) makes such a thing that sort of thing, one which contains within itself its own conditions of identity, continuity and

32 DA 2.2, 413b5-8; 2.3, 414a33-b1; 415a1-3; the two are discussed together at 2.4, 415a23-b1, and explicitly identified at 2.4, 416a19-21.

${ }^{33}$ Ross's note (1961, pp. 166-7) on the etymology and general ambit of entelecheia in Aristotle, is both clear and well worth reading; "it seems that strictly speaking energeia means activity or actualization, whereas entelecheia means the resulting actuality or perfection". Ross draws this conclusion on the basis of Metaph $\Theta .8,1050 \mathrm{a} 21-3$; but as he goes on to note, Aristotle generally seems to use the two terms interchangeably. For all that, entelecheia is particularly prominent in DA 2-3. See also Beere (2009, pp. 161-3); Shields (2016, p. xii, n 2). 
reproducibility. ${ }^{34} \mathrm{D} 2$ further specifies that the appropriate sort of potentially living body is so because it can function as an instrument of the soul's intrinsic functions; while D3 simply puts all of this together in its most compendious form.

'Natural bodies' are all those which contain any form of internal principle of change and rest (Phys. 2.1, 192b8193a10), and as such include the elements (192b8-23; cf. $D C$ 3.1). But life is predicable only of a sub-class of those bodies, namely those which are such as to be alive; and these are so because they are in some important sense instrumental (organikon) for the soul (this is why the soul is a proper subject of inquiry for the phusikos). So the ensouled body, considered as the vehicle for the soul, subserves the soul's ends by being what the soul achieves those ends with. Finally, it is the first actuality: it is what makes the body such as to be capable of carrying out those ends, without being always in the condition of actually carrying them out. To be alive is to have certain capacities, but not (necessarily) always to be exercizing them; and (at least in most cases) contingently not to be always so exercising them. The soul is a first actuality (or second potentiality);35 and as such it is like dispositional, as opposed to occurrent, knowledge (DA 2.1, 412a21-7). Indeed, this is how the soul is something "which exists in potentiality" ( $D A 1.1$.

34 For discussion of whether essences are entities, see Angioni 2014, pp. 107-9.

35 Aristotle sometimes, as here, distinguishes mere potentiality from $1^{\text {st }}$ and $2^{\text {nd }}$ actuality, and sometimes $1^{\text {st }}$ and $2^{\text {nd }}$ potentiality from full actuality (as, using the same example of knowledge, at $D A 2.5,417 \mathrm{a} 22-30)$. The difference is one of perspective only; one may think of someone in one and the same state either as not fully knowing (i.e. not actually knowing, and so being in a state of potentiality in relation to the latter condition), or as really, actually knowing, but just not exercizing that knowledge. 
402a25-6). ${ }^{36}$ To be alive, one might say, is to have a certain (developing) set of actualized capacities (including metabolism, reproduction, self-maintenance and selflimitation, and perhaps also locomotion, perception, and the various forms of intellection). What it is to be alive (at any position on the scala naturae) is to be actually capable of doing the sorts of things that creatures at that level can typically do. But it is not always to be actually doing them. ${ }^{37}$

\section{STARTING FROM THE MOST General: THE NuTRITIVE SOUL OF DA 2.4}

Aristotle lays out his basic structural account in $D A 2.4$. We start with the most general attribute which everything of which it is true to say that it really is alive will share, namely the capacity to metabolize and produce examples of one's own kind: in short, what is covered by the nutritive (and equivalently, at least extensionally, the generative: see n 34) capacity. Before he goes any further, Aristotle begins by laying down some more basic methodological principles that will articulate the process. First of all, when

\footnotetext{
${ }^{36}$ Here it is raised as a question, whether it "exists in potentiality" or as an entelecheia; but the point of D1-3 is precisely that it is in a sense both; see Shields (2016, pp. 87-8).

37 The most basic and general part of the soul, that which defines life as such, the nutritive, is problematic here, since it is, as Philoponus (among others) notes, always active as long as the living thing is. But Aristotle may perfectly well allow that some of these functions are in a state of constant actuality, just to keep the organism ticking over; in these cases, there will be no distinction between first and second actuality. Even in these cases, the functional activities may be variable in their degree of realization - take the fundamental nutritive capacity of digestion, for example.
} 
considering the general capacities that will define what it is to be alive, and in what way, you have to grasp the ti esti of each of these things, what they (definitionally) are, and then what depends upon them, their idia sumbebêkota. However, in order to give the ti esti of perceptive, nutritive and intellectual faculties, we need to say what perceiving and metabolizing actually are; moreover, if their correlative objects (antikeimena), perceptibles and food, are prior to the activities, we will need to know, in advance of anything else, what they are too (415a16-22; cf. 1.1, 402b9-16). Thus we should start with nutrition and generation; the nutritive soul is the "first and most common power of the soul" (prôtê kai koinotatê dunamis psuchês) in terms of which life belongs to all living things. Its erga, its primary tasks, are to reproduce, and to employ food for growth and self-preservation and maintenance (415a22-6). The most natural ergon for living things that are complete, and neither deformed nor spontaneously generated, is to make another of the same kind (and thus to most closely approximate the divine: 415a26-b1). Everything desires this, and does what it does naturally for the sake of it (415b1-7). This is the most general teleological principle that animates the natural world: what absolutely every living thing, in the sublunary world at least, is, in some sense for.

This supplies the fundamental architecture for what I want to call the pure science of the soul. The basic idea is this. Systems which are capable of reproducing, and hence perpetuating, their own (species) form, and thus of achieving a sort of quasi-immortality, must be able to maintain and preserve themselves at least until they can take advantage of reproductive maturity. And anything capable of that must also be capable of seeking out and acquiring nutritive material, and also be able to do whatever is needed in order to transform that material into living tissue. This also, partially, clarifies the nature of the relation between the nutritive and reproductive capacities. They are 
(at least) extensionally equivalent; although (I suggest) there is a non-trivial sense in which nutrition is ultimately for the sake of reproduction. But for all that they are materially and organically quite distinct. Indeed, facts of their material and organic instantiations are quite irrelevant to their formal inter-relationships, which form the subject-matter of pure psychology.

Moreover these types of relations can be exhibited syllogistically, in the approved Aristotelian manner:

(Ai) Any living thing must be capable of selfmaintenance and reproduction.

(Aii) Anything capable of self-maintenance and reproduction must be able to seek out and process its own nutritive material.

So

(Aiii) Any living thing must be able to seek out and process its own nutritive material.

The precise details of such syllogistic schemata, and how they are to be filled out will obviously be controversial; but we need not pursue those hares any further. What matters is simply that these relations exhibit centrally the phenomenon of hypothetical necessity, which is in turn central to Aristotle's understanding of his own teleological commitments. ${ }^{38}$

38 On hypothetical necessity, see fundamentally Cooper (1985), (1987); and Charles (1988). 


\section{TEleology aNd Hypothetical NECESSity, AND THE PuREly Formal SCIENCE OF THE SOUL}

So let us now turn to that, and to the relations that hold generally and purely formally - between the various types of animal and the nutritive and perceptive souls. Animals are characterized, in general, by their capacity for sensation and autonomous motion, ${ }^{39}$ for the acquisition of food and the avoidance of danger. The most fundamental - and hence most widely distributed - sense is that of touch $(D A$ 2.2, 413b4-10): any animal must, definitionally, have at least that. But the definition encodes teleological facts about the living world, all of which ultimately derive from the basic Aristotelian teleological slogan that nature does nothing in vain $(P A$ 2.13, 658a8-9; 3.1, 661b23-4; 4.12, 694a14-15, etc), and the related, although non-equivalent, claim that it always acts for the sake of the best. ${ }^{40} D A 3.12$ spells these relations out. All living things necessarily have a nutritive soul (434a22-6); but only those which have complex bodies, and are "capable of receiving the forms without the matter" 41 have perception (434a27-30):

An animal necessarily has perception, if nature does nothing in vain. For everything which exists by nature exists for the sake of something, or is a consequence of things which exist for the sake of something. Any

39 The precise sense of 'autonomous' here is controversial: see the essays collected in Lennox and Gill (1994), esp. Furley, Gill, Sauvé-Meyer, and Freeland; and Hankinson, forthcoming.

40 PA 1.1, 641b12; 4.10, 687a15; see Lennox (1997), and (2001, p. 231).

41 The 'perceptible form', which is assimilated to a ratio: see 2.12, 424a17-24; see Caston (1998) 
body capable of locomotion and which did not have perception would be destroyed and would not achieve its goal [sc. of reaching reproductive maturity], which is nature's ergon. (18: DA 3.12, 434a27-b1)

There are some immoveable, sessile animals, which also have the sense of touch - but they get their nourishment from their immediate environments, as plants do, whereas no body without perception can have a discriminatory faculty (434b1-8). These immoveable animals, though, can still react to things in their immediate environment by touch, and to do so require a complex, differentiated body (434b9-10), i.e., one capable of taking on the properly tactile properties, since there can be no sensation without (a type of) alteration. ${ }^{42}$ Although plants "have one soul-part, and are affected in a way by the objects of touch, i.e., they are cooled and heated", they do not perceive, since they do not have the appropriate archê for taking on the forms of perceptibles, but "rather are only affected along with matter," that is by direct physical contact ( $D A$ 2.12, 424a32-b3). By contrast,

The animal's body must be capable of touch if it is to survive.... For when it is touched, if it does not have perception, it will not be able to

\footnotetext{
${ }^{42}$ Cf. 2.4, 415b24, 2.5, 416b34-5: 'alloiosis tis'. The force of the 'tis' is disputed - does it mean (roughly) "a sort of alteration" or "alteration of a sort" (i.e, not genuine, honest-to-goodness alteration)? This matters particularly to the dispute between 'spiritualists' (following the recent deflationary account of Myles Burnyeat) and their 'literalist' opponents (see Burnyeat (1992), (2003); Sorabji (1974); Everson (1999); Caston (2005); see also 417b2-16, and Shields (2016, pp. 212-13, 217-19, and in general pp. xxxii-xxxix). Again, we need take no sides on the matter.
} 
flee from some things and to get hold of others, and if this [is the case], the animal will be incapable of preserving itself. The other senses perceive by way of [or: through] other things. This is why taste too is a sort of touch, since it is of nourishment, and nourishment is a tangible body. Sound, and colour, and smell do not nourish, nor do they produce growth and decay; consequently then taste is necessarily a sort of touch, because it is perception of what is tangible and nutritive. These latter senses, then, are necessary for the animal, and indeed clearly it cannot even be an animal without touch, while the other senses are for the sake of well-being, ${ }^{43}$ and belong to particular, and not all, types of animal. But for those which can move from place to place, these senses must exist, since to preserve themselves they need to perceive not only by contact, but also from a distance. (19: $D A$ 3.12, 434b13-27)

This passage spells out the basic relations that hold between living, the acquisition of nutrition, and preservation. The primacy of touch depends on the fact that animals are embodied, and hence vulnerable to damage by contact, and hence that it will be of benefit to them to be able to move to avoid damage, even if only minimally so. This in turn accounts for why taste, the sense primarily charged with discriminating good and bad nutrition (cf. 2.3, $414 \mathrm{~b} 7-14$ ), is a contact sense, indeed a kind of touch (cf. 2.10, 423a8).

43 I.e. not for merely being an animal, but for being a good example of the (general) kind: cf. 20, and Sens. 1, 436b8-437a3. 
Distance senses, on the other hand, serve more specialized functions, and allow the locomotive animal to anticipate both beneficial and harmful encounters prior to actual contact:

An animal has the other senses, not just for the sake of being [sc. an animal]... but for the sake of being one well. For example sight, because it lives in air or water (or generally in something transparent), so that it can see, taste $^{44}$ on account of the pleasant and painful, so that it might perceive what there is that is nutritive, and desire it, and move towards it. (20: DA 3.13, 435b19-24)

These are not strictly speaking necessary, even for an animal that moves from place to place; but they contribute significantly to any such animal's success (and of course they would also be useless for any sessile animal, at least insofar as self-preservation was concerned). All of these relations, even if their details may be controversial, can be exhibited in the form of syllogistic expressions of teleological dependency. And that, I suggest, is the form that a pure Aristotelian science of the soul will take. The type of syllogistic relation between properties generally and purely formally conceived which I have in mind may be illustrated by the following example (owed to Jonathan Barnes, 1994, 231, but suggested by $D A 1.1,403 \mathrm{~b} 3-7)$ :

(Bi) Houses are shelters;

44 'Taste', geusis, is unexpected here, since it is not a distance sense; perhaps an error for 'smell' (osmê)? The sense of smell is, as Aristotle recognizes, in some sense analogous to that of taste: 2.9, 421a16-b8. 
(Bii) Anything that shelters must be roofed;

So

(Biii) Houses must be roofed.

Here the middle term ('shelter') is both formal and final; the minor premiss $(\mathrm{Bi})$ is an axiom of form and finality for the quasi-species 'house', and is definitional; the major premiss (Bii) involves hypothetical necessity, and implies the necessity of material components - but not of any particular type of material component. My suggestion is that precisely congruent sorts of relation are exemplified between the properties that constitute the capacities of the soul, of the sort sketched in $\mathbf{1 9}$ and $\mathbf{2 0}$. I shall not try to set them all out here. ${ }^{45}$ However, consider the following syllogism:

(Ci) All animals capable of desire are susceptible of pleasure and pain;

(Cii) Anything susceptible of pleasure and pain is capable of movement;

So

(Ciii) All animals capable of desire are capable of movement (DA3.10, 433b22-30).

45 While it might be instructive to do so, not least in order to exhibit the difficulty of squeezing some at least of Aristotle's explanatory relations into syllogistic form, it would certainly be controversial, and at best exempli gratia. My concern is with how it is possible for Aristotle to conceive of a science of the soul, not to reconstruct it. 
(C) is (perhaps) a demonstration in pure psychology, and (Ciii) a theorem of that science. But the direction of explanation may be controversial, since (Cii) presumably converts; and if so, its converse (Cii*), along with (Ciii), will entail (Ci):

(Ciii) All animals capable of desire are capable of movement;

(Cii*) Anything capable of movement is susceptible of pleasure and pain;

So

(Ci) All animals capable of desire are susceptible of pleasure and pain.

Call this inference $\left(\mathrm{C}^{*}\right)$. At most one of $(\mathrm{C})$ and $\left(\mathrm{C}^{*}\right)$ can, for Aristotle, be genuinely explanatory (cf. Post.An. 1.13, 78a22-b11; 2.16-17). So do animals capable of desire move because they can feel pain, or do they feel pain because they can move? One might think that for Aristotle it is the former that is relevant, and for teleological reasons: the only point to being capable of autonomous movement is to be able to pursue pleasurable things, and to avoid painful ones. On the other hand, desire is tightly linked to pursuit and avoidance, and that explains the functional role of pleasure and pain. Pleasure and pain (actual or anticipated) cause us, as efficient causes, to pursue and avoid, and there is a sense in which we move in order to experience pleasure or avoid pain: they are the goals of our appetitive action. But these are, from the point of view of the organizational structure of nature itself, only intermediate goals. We are so structured to respond to such stimuli in order to further our very general goal of self-preservation; and equally there would be no point in experiencing pleasure and pain if we 
could not so respond, by taking pursuing or evasive action. What animals find pleasurable should, then, in general be good for them, in the sense of conducing, nutritively or otherwise, to their preservation; and contrariwise with pain (this raises large and pressing questions regarding harmful pleasures; but we can leave those on one side). For, as we know, nature does nothing in vain.

Matters are clearly complicated, and it would be no easy task to construct a definitive tree of the appropriate functional relations. Efficient and teleological considerations play a complex and interwoven role. Moreover, there are also different types of dependencyrelation in play. We may distinguish between teleological dependency, where the lower depends on the higher, in that the latter is what it is for); and supporting dependency, where the higher depends upon the lower, in the sense that the higher cannot exist/function without the lower, and which may be thought of, in this sense, as material or instrumental for it. ${ }^{46}$ Both of these may (and under certain conditions will: Post.An. 2.16-17) involve entailment, in the sense of the holding of (at least) extensional relations between the

\footnotetext{
46 This relates to the issue of whether there is an attenuated sense in which the nutritive soul can be thought of as being the matter for the various types of animal soul, in that in definition the genus can, for Aristotle, be considered as the matter, the differentia as the form. Compare Metaph. Z.10, 1056a9-12 on the restriction of 'intelligible matter' by form: the form 'circle' is imposed on the matter of 'plane extension'. Perhaps Aristotle simply tries to do too much with his matter/form distinction. In any case, having an animal soul is not really a determination of a type of nutritive soul, although it does point to restriction of the general class of all things which possess the nutritive soul. Still less is the animal soul itself a distinctive mode of the nutritive soul, analogous to the way in which, e.g., being a biped is a way of having feet (see $P A$ 1.2-3, on appropriate, and inappropriate, types of process of division).
} 
items in question. In certain cases, and with certain stipulations, these too may be inter-entailing, i.e. they will be expressible in terms of commensurate universals.

But in general, these relations will involve the specification of the ways in which different types of bodypart fulfil their various functional roles, and as such they will not be part of any pure science of the soul. Note the different ways in which 'teleological' syllogisms may be constructed out of, e.g., PA 3.3, 664a12-b2.47 Nor will the pure science of the soul involve the kinds of teleological relations that hold between animals and their parts in virtue of their modes of living, their size, their differential needs for nutrition and so on: all the sorts of things, in fact, that $P A$ deals with. In these cases, optimal solutions are crucially dependent upon bodily and material facts. ${ }^{48}$ And the same is true of the "things common to body and soul", essentially the subject-matter of the Parva Naturalia, such as emotions when properly defined, as a phusikos would, to include their material bases (16 above). Even so, there is a point in concentrating on the formal aspect, even though,

${ }^{47}$ Lennox (2001a, pp. 250-2): "Not all animals have this part [sc. the neck], but only those with parts for the sake of which the neck is naturally present; and these are the larynx and the part called the oesophagus". Lennox (p. 251) plausibly, if slightly artificially, reconstructs an explanatory syllogism as follows: "(P1) Necks belong by nature to everything with what necks are for. (P2) Having what necks are for belongs to everything with a larynx and an oesophagus. (C1) Necks belong to everything with a larynx and an oesophagus". All of these, of course, involve specifying the material, in more than one sense, components of the animals' bodies.

48 Indeed, particular bodily and material facts - this is why the particularized locomotive properties (walking, crawling, swimming, etc.) are used in $P A$ to differentiate types of animal: cf. e.g. $P A 4.8,4.11$. 
strictly speaking, the soul is not the proper subject of affective predication. As Aristotle says (DA 1.4, 408a33$\mathrm{b} 18)$, although we say that the soul is distressed or pleased, fearful, confident or afraid or angry, this is a mistake. These things are caused by the soul, but they are bodily affections:

to say that the soul is angry is rather as if one were to say that soul weaves or builds; and it is perhaps better not to say that soul pities, or learns, or thinks, but rather that the man does these things with $^{49}$ his soul. (21: DA 2.4, 408b12-15)

\section{CONCLUSIONS}

It is time to draw some - pretty provisional - conclusions from all of this. First of all, Aristotle thinks of soul, in all of its manifestations, as inducing a particularly tight type of unity in the things for which it supplies the form. This is the point of the comparison with the axe in $D A 2.1$ :

We have expressed in general what the soul is: it is the essence in accordance with the formula (ousia... he keata ton logon). And this is the what-it-is-to-be (to ti ên einal) ${ }^{50}$ of this kind of body, just as if one of the instruments, for example an axe, had been a natural body: being for an axe would have been its ousia, and thus its soul. And if this were separated from

\footnotetext{
${ }^{49}$ Not of course instrumentally, but agentively; this is part of the argument against the idea that the soul, as a motion-causer, must be in motion.

50 Aristotle's preferred term for substantial essence: Metaph. Z4-6, 10-11.
} 
it, it would no longer be an axe, other than homonymously; but now it is an axe. But it is not of this kind of body that the to ti en einai and formula is the soul, but only one which is natural, i.e. which has within itself its origin of motion and rest. (22: DA 2.1, 412b10-17)

The regularly-repeated claim that a dead eye (or hand) is an eye (or hand) only homonymously (412b19-22; cf. PA 1.1, 641a18-21, etc.) points to a crucial difference between natural and artifactual objects. A blunt axe is still an axe, albeit a very bad one (and of course it can be re-sharpened, unlike a dead eye; although note the thought-experiment of 1.4, 408b20-2: if an old man were given a young man's eye, he would see as well as he ever did). The deterioration of the function is to be ascribed to the deterioration of the organic basis of that function - but the latter is irreversible and irremediable. That unity also derives from the selflimiting nature of the soul. Living things grow and develop only up to a certain point - their mature, reproductivelycapable form - and then they stop, and the nutritive functions continue simply to maintain and preserve it (at least insofar as they are able to do so; death and decay are eventually inevitable in the sublunary world: $D A 3.12$, 434a22-6). This is why fire as such cannot be the essence of soul, but only some crucial instrumental component of it, since fire, given a suitable supply of nutritive material, will simply grow unchecked ( $D A 2.4,416 a 9-18)$.

This point has to do crucially with the distinction between the internal and the external imposition of form. A craftsman induces form in his chosen material from the outside; the natures of living things permeate them through and through (see Metaph. Z.7-8). In living things, after their initial generation, their source of development and maintenance is internal, and dynamic ( $G A$ 2.1-3). Indeed, this is precisely what distinguishes the biosphere from 
everything else, and what determines, in its broadest extension, the realm of the soul, and hence the subject of its partially abstract science. But it is still a science only in a fairly attenuated sense. The pure science of the soul is the scaffolding for the properly filled-out claims about the real natures of animals - particular types of animals - and their material instantiations. It will play a role analogous to that of abstract geometry in optics, and arithmetic in harmonics. But it will never be a more or less free-standing science in the way that the mathematical sciences are, since it will never really have its own fully-abstracted subject terms (line, point, unit, number, etc.). It will essentially be about predicates, or items in the category of quality, and not (directly) about substances - even quasi-substances - as such at all. But the implicit subjects of the fully-elaborated syllogisms will be 'living things', 'plants', 'animals', and so on. ${ }^{51}$

${ }^{51}$ A version of part of this was presented for "Explanation and Essence: 4th Campinas Conference on Aristotle's Theory of Science", at the University of Campinas, Campinas, Brazil, on May 22 ${ }^{\text {nd }}, 2017$; another version of some other parts (largely), was presented to the UT/UNAM X Encuentro Philosophico, at UNAM, Mexico City, on October 28 $8^{\text {th }}, 2017$. Yet another iteration was inflicted on the tolerant audience of the Utrecht History of Philosophy Colloquium on May 3 $3^{\text {rd }}, 2018$. I am grateful to my commentator in Mexico, Martín Barbosa, and the audiences on all three occasions for some helpful comments. In addition Martín sent me a very lengthy and detailed response outlining the issues he had with my treatment. I have attempted to deal with at last some of them - but I fear my amendments and clarifications will not satisfy him. I would like to thank the editors of the Manuscrito issue, Lucas Angioni and Breno Zuppolini, for their helpful comments. 


\section{REFERENCES}

ANGIONI, L. 2014. "Aristotle on Necessary Principles and on Explaining X through X's essence". Studia Philosophica Estonica 7.2, pp. 88-112.

2018. "Causality and coextensiveness in Aristotle's Posterior Analytics 1.13", Oxford Studies in Ancient Philosophy 54, pp. 159-185.

BARNES, J. 1985. "Aristotelian arithmetic", Revue de la philosophie ancienne 1, pp. 97-133. Repr. in Barnes (2011), pp. 334-63. 1987. "An Aristotelian way with scepticism", in M.Matthen (ed.), pp. 51-76. Repr. in Barnes (2014), pp. 586-610.

1994. Aristotle: Posterior Analytics Clarendon Aristotle Series. Second Edition. Oxford: Oxford University Press.

2011. Method and Metaphysics. Essays in Ancient Philosophy I. Oxford: Oxford University Press. 2014. Proof, Knowledge, and Scepticism. Essays in Ancient Philosophy III. Oxford: Oxford University Press.

BARNES, J., SCHOFIELD, M. and SORABJI, R.R.K. 1979. Articles on Aristotle Vol. 3: Metaphysics. London: W.H.Duckworth. and 1979. Articles on Aristotle Vol 4: Psychology and Aesthetics. London: W.H.Duckworth.

BEERE, J. 2009. Doing and Being: An Interpretation of Aristotle's Metaphysics Theta. Oxford: Oxford University Press. 
BURNYEAT, M. F. 1992. "Is an Aristotelian philosophy of mind still credible? (A Draft)" in M.C.Nussbaum and A.O.Rorty (eds.) (1992), pp. 15-26. 2002. “De Anima II 5”, Phronesis 47, pp. 28-90.

CAston, V. 1998. "Aristotle and the problem of intentionality", Philosophy and Phenomenological Research 58, pp. 249-98.

2005. "The spirit and the letter: Aristotle on perception”, in R.Salles (ed.)(2005), pp. 245-320.

CHARLES, D. 1988. "Aristotle on hypothetical necessity and teleology”, Pacific Philosophical Quarterly 59, pp. 1-53.

COOPER, J. 1985. "Hypothetical necessity", in A. Gotthelf (ed.) (1985), pp. 151-67.

1987. "Hypothetical necessity and natural teleology", in A. Gotthelf and J. Lennox (eds.) (1987), pp. 24374.

Devereaux, D. and Pellegrin, P. (edd.). 1995. Biologie, logique et métaphysique chez. Aristote. Paris: Editions du CNRS.

Everson, S. 1999. "Proper sensibles and kath' hauta causes", Phronesis 40, pp. 265-92.

FREDE, M. 1995. "The definition of sensible substances in Metaphysics Z", in D. Devereux and P. Pellegrin (edd.)(1995), pp. 113-29.

FREELAND, C. 1994 "Aristotle on perception, appetition and self-motion", in M.L.Gill and J. Lennox (edd.) (1994), pp. 35-63.

FurLEY, D. 1978. "Self-Movers", in G.E.R. Lloyd and G.E.L. Owen (eds.) (1978), pp. 165-79. Repr. in M.L. Gill and J.G. Lennox (edd.)(1994), pp. 3-14. 
GILL, M.L. 1994. "Aristotle on self-motion", in Gill and Lennox (edd.)(1994), pp. 14-34. and Lennox, J.G. (edd.). 1994. Self-Motion. Princeton: Princeton University Press.

GotThelf, A. 1985. Aristotle on Nature and Living Things. Pittsburgh and Bristol: Mathesis Publications. and Lennox, J.G. (edd.) 1987. Philosophical Issues in Aristotle's Biology. Cambridge: Cambridge University Press.

GÜNTHER, H.C. and RenkAgOs, A. (edd.). 1997. Beiträge zur antiken Philosophie: Festschrift für Wolfgang Kullmann, Stuttgart: Steiner Verlag.

HANKINSON, R.J. 2005. "Aristotle on kind-crossing", in R.W.Sharples (ed.) (2005), pp. 23-54.

(forthcoming) "Aristotle and the mechanics of desire", in C.Rapp and O.Primavesi, (eds), Proceedings of the XIX Symposium Aristotelicum, Munich 2012.

INWOOD, B. 1979. "A note on commensurate universals in the Posterior Analytics", Phronesis 24, pp. 320-9.

LEAR, J. 1982. "Aristotle's philosophy of mathematics", Philosophical Review 91, pp. 161-192.

LENNOX, J.G. 1997. "Nature does nothing in vain...", in H.-C.Günther and A.Rengakos (eds.) (1997), pp. 199-214. Repr. in J.G.Lennox (2001b).

2001a. Aristotle: On the Parts of Animals I-IV Clarendon Aristotle Series. Oxford: Oxford University Press.

2001b. Aristotle's Philosophy of Biology: Studies in the Origins of Life Science. Cambridge: Cambridge University Press. 
2005. "Zoology in Aristotle's natural philosophy", in R.W.Sharples (ed.) (2005), pp. 55-71.

LLOYD, G.E.R. and Owen, G.E.L. 1978. Aristotle on Mind and the Senses, Cambridge: Cambridge University Press.

Matthen, M. 1987. Aristotle Today. Apeiron Supp. Vol. 20. Edmonton: Academic Printing and Publishing.

MUELLER, I. 1970. "Aristotle on geometrical objects", Archiv fur der Geschichte der Philosophie 52, pp. 156-171. Repr. in J.Barnes, M.Schofield, and R.R.K.Sorabji (eds.)(1979), pp. 96-107.

Nussbaum, M.C. and RORTY, A.O. 1992. Essays on Aristotle's de Anima. Oxford: Oxford University Press.

Ross, W. D. 1961. Aristotle de Anima. Oxford: Oxford University Press.

SALLES, R. (ed.). 2005. Metaphysics, Soul, and Ethics. Oxford: Oxford University Press.

Sharples, R. W. (ed.) 2005. Philosophy and the Sciences in Antiquity. Aldershot: Ashgate.

SHIELDS, C. 2016. Aristotle: de Anima, Clarendon Aristotle Series. Oxford: Oxford University Press.

SORABJI, R.R.K. 1974. "Body and soul in Aristotle", Philosophy 49, pp. 63-89. Repr. in J.Barnes, M.Schofield, and R.R.K.Sorabji (eds.)(1979), pp. 4264.

$(\infty))_{B Y}$ 